\title{
PERANAN METODE CERAMAH DALAM MENINGKATKAN PRESTASI BELAJAR SISWA KELAS VI PADA BIDANG STUDI PENDIDIKAN AGAMA ISLAM DI SD AL-MUZZAMMIL BEKASI
}

\author{
Zainal Muttaqin \\ UniversitasMuhammadiyahTasikmalaya \\ Jl. Tamansari Km.2,5 Tamansari Kota Tasikmalaya \\ Email: zenmuttaqin83@gmail,com
}

\begin{abstract}
Abstrak
Metode dalam proses pendidikan adalah salah satu hal penting yang berkontribusi untuk menentukan keberhasilan guru kepada siswa dalam mencapai tujuan pengajaran. Seorang guru dapat diklasifikasikan sukses dalam mengajar jika dia menggunakan metode yang baik dan sesuai dengan kebutuhan siswa. Untuk mengusahakan pendidikan agama islami dapat diterima oleh peserta didik, maka seorang guru harus menggunakan metode yang tepat dan sesuai dengan situasi dan kondisi. Dalam hal ini guru dapat menggunakan beberapa metode tergantung pada materi yang akan disampaikan dan kondisi peserta didik itu sendiri. Kompatibel antara materi pelajaran dan metode dan penerapan metode ini sangat penting. Hal ini dimaksudkan untuk menghindari kegagalan dalam mencapai tujuan pendidikan yang digariskan pada setiap mata pelajaran. Oleh karena itu seorang guru perlu menemukan dan menceritakan metode mana yang lebih tepat untuk diterapkan dalam pengajaran. Tujuan penelitian ini adalah untuk mengetahui apakah ada peran metode ceramah dalam meningkatkan prestasi belajar siswa kelas enam di bidang Pendidikan Agama Islam di ALMuzzammilElementary School Bekasi. Metode yang digunakan dalam penelitian ini adalah metode deskriptif yang mengisahkan, menganalisis, dan mengklasifikasikan dengan teknik survei, wawancara, kuesioner, observasi, dokumentasi atau dengan teknik tes dan pengolahan data menggunakan persentase. Sedangkan interpretasi data adalah untuk menentukan skala perhitungan dari $1 \%$ hingga $100 \%$ sebagai berikut: $61 \%$ hingga $99 \%$ menyatakan paling banyak, $51 \%$ hingga $60 \%$ menyatakan lebih dari setengah, 50\% menyatakan setengah, $40 \%$ hingga $49 \%$ menyatakan hampir setengah, $1 \%$ hingga $39 \%$ menyatakan sebagian kecil, dan 0\% menyatakan tidak ada sama sekali. Setelah data terkumpul, kemudian diolah, dianalisis dan disimpulkan. Dari hasil penelitian, diketahui bahwa 85\% guru pendidikan agama Islam selalu menggunakan metode ceramah, $75 \%$ siswa menyukai metode ceramah dalam pembelajaran, $65 \%$ siswa dapat dengan mudah memahami pelajaran PAI dengan metode ceramah, $75 \%$ siswa tidak menemukan kesulitan dalam memahami kata-kata atau pidato guru PAI dengan menggunakan metode ceramah, $90 \%$ dengan metode ceramah prestasi siswa ada peningkatan. Dari hasil penelitian ini, penulis dapat mengambil satu kesimpulan bahwa "Metode Ceramah berperan dalam meningkatkan prestasi siswa dalam pendidikan agama Islam".
\end{abstract}

\section{Kata Kunci: \\ Metode Kuliah; Peningkatan Prestasi Belajar Siswa; Pendidikan Agama Islam.}

\begin{abstract}
Methods in the process of education is one of the important things that contribute to determine the success of teachers to students in achieving teaching objectives. A teacher can be classified success in teaching if he / she uses a good method and appropriate to the student's needs. To strive the islamic religious education can be accepted by learners, then a teacher must use appropriate methods and in accordance with the situation and conditions. In this case the teacher can use several methods depending on the material to be delivered and the condition of the learners themselves. The compatible between the subject matter and the method and application of the method is very important. It is intended to avoid the failure in achieving the educational goals outlined on each subject. Therefore a teacher needs to find and narrate which method is more appropriate to apply in teaching. The purpose of this study is to determine whether there is the role of lecture methods in improving the sixth grade students'learning achievement of in the field of Islamic Religious Education in ALMuzzammilElementary School Bekasi. The method used in this research is descriptive method that that tells, analyzes, and classifies with survey technique, interview, questionnaire, observation, documentation or with test and data processing technique using percentage. While the interpretation of the data is to determine the scale of calculation from $1 \%$ to $100 \%$ as follows: $61 \%$ to $99 \%$ stated most, $51 \%$ to $60 \%$ stated more than half, $50 \%$ stated half, $40 \%$ to $49 \%$ stated almost half, $1 \%$ to $39 \%$ stated a small part, and $0 \%$ stated none at all.After the data collected, then processed, analyzed and concluded.
\end{abstract}


From the results of the research, it is known that $85 \%$ of teachers of Islamic religious education always use lecture method, $75 \%$ of students like the lecture method in learning, $65 \%$ of students can easily understand the lesson of PAI by lecture method, $75 \%$ of students find no difficulty in understanding the words or speech of PAI teacher with the use of lecture method, $90 \%$ with lecture method of student achievement there is improvement. From the results of this study, the authors can take one conclusion that "Lecture Method plays a role in improving student achievement in the Islamic religious education".

Keywords:

Lecture Method; Improvement of Student Learning Achievement; Islamic Religious Education.

\section{A. PENDAHULUAN}

Dalam aktifitas pendidikan, guru sebagai pelaksana utama dituntut untuk melaksanakan tugasnya secara professional dan memerlukan wawasan yang luas dan utuh tentang kegiatan belajar mengajar. Seorang guru harus mengetahui dan memiliki pengetahuan secara menyeluruh mengenai bagaimana proses belajar mengajar itu terjadi serta langkahlangkah apa yang diperlukan sehingga tugastugas keguruannya bisa dilakukan dengan baik dan sesuai dengan tujuan yang diharapkan. (Mansyur Syah, 1992).

Bidang studi Pendidikan Agama Islam merupakan pelajaran yang berperan dalam pembentukan kepribadian siswa. Untuk itu, metode guru dalam mengajar mutlak diperlukan. Sehingga pembentukan kepribadian siswa sesuai yang dikehendaki oleh Islam berdasarkan Al-Qur'an dan As-Sunnah yang telah diterapkan oleh Rosululloh SAW dan para Sahabatnya serta para pendidik muslim terdahulu sehingga prestasi belajar siswa pun sesuai dengan yang diharapkan. (Hilmy Bakr Al-Mascaty, 1999).

Pendidikan yang telah diterapkan oleh Rosululloh SAW adalah pendidikan yang diturunkan Alloh SWT sang pencipta manusia, yang maha mengetahui tentang manusia yang diciptakannya. Itulah sebabnya pendidikan Rosululloh SAW menjadi pendidikan yang terunggul karena mengetahui benar tentang hakikat manusia dan dengan segala sesuatu yang berkaitan dengannya. (M. Nur Abdul Hafidz, 1994). Maka tidak diragukan lagi bahwa pendidikan Rosululloh SAW telah berhasil melahirkan manusia-manusia unggul dan agung seperti Abu Bakar Assiddiq, Umar bin Khathab, Utsman bin Affan, Ali bin Abi Thalib, Abdurrahman bin Auf, Bilal bin Robah, Amar bin Yasir, dan ribuan manusia-manusia unggul lainnya yang menjadi mercusuar peradaban umat manusia, kapan pun dan dimana pun asalkan diterapkan sebagaimana Rosululloh SAW menerapkannya. (Wahid Abd Salam, 1992).

Dari sekian banyak faktor yang mempengaruhi kualitas pendidikan, diantaranya adalah faktor metode guru dalam proses belajar mengajar. Artinya, berhasil atau tidaknya proses belajar akan banyak ditentukan oleh sejauh mana guru mampu memainkan perannya, sehingga guru harus benar-benar mengetahui strategi proses belajar mengajar dengan baik, benar dan tepat sesuai dengan aturan yang telah ditetapkan. (Abu Ridha, 1994).

Dari uraian tersebut dapat disimpulkan bahwa dalam proses belajar mengajar metode guru mempunyai peranan yang sangat penting untuk meningkatkan prestasi belajar siswa sehingga mereka benar-benar mempunyai kemampuan yang dapat diandalkan. Dengan latar belakang masalah tersebut, maka penulis merasa perlu untuk meneliti tentang peranan metode ceramah dalam meningkatkan prestasi belajar siswa kelas enam pada bidang studi Pendidikan Agama Islam di SD ALMuzzammil Bekasi. 


\section{B. HASIL DAN PEMBAHASAN}

\section{Hakikat Metode Ceramah}

Yang dimaksud dengan metode ceramah ialah sebuah bentuk interaksi melalui penuturan secara lisan oleh seorang guru atau pendidik terhadap siswanya. Dalam pelaksanaan metode ceramah untuk menjelaskan uraiannya, guru dapat menggunakan alat-alat bantu seperti gambar-gambar dan lainnya, tetapi alat untuk berinteraksi dengan siswa adalah bahasa lisan. Peranan siswa dalam metode ceramah adalah mendengarkan dengan teliti serta mencatat pokok-pokok bahasan yang dikemukakan oleh guru.

Apabila seorang guru menggunakan metode ceramah dalam proses belajar mengajar, maka:

1. Dapat menguasai seluruh kelas, karena ketertiban kelas mudah dijaga.

2. Organisasi kelas sederhana. Ini berarti guru tidak perlu mengadakan pengelompokkan siswa. Guru tinggal berdiri didepan kelas sambil menjelaskan materi, sedangkan siswa mendengarkan sambil mencatat.

3. Dapat memberikan penjelasan yang sama kepada sejumlah siswa tentang materi pelajaran yang sulit dan penting dalam waktu relative singkat.

4. Hal-hal yang penting dan mendesak dapat segera disampaikan kepada para siswa.

\section{Hakikat Prestasi Belajar}

Kita semua ingin dihargai karena kerja keras dan prestasi kita, begitu juga anak-anak. Apalagi anak lebih cenderung memilih dan menikmati hal-hal yang memberikan penghargaan padanya. Jadi salah satu factor yang mendorong anak mau mengerjakan tugas sekolah ialah karena diberi hadiah atas prestasi yang telah di capainya di sekolah. Sebagaimana dikatakan oleh Claire Safran, seorang ahli pendidikan "Prestasi dengan sendirinya sudah menjadi hadiah, namun untuk mendapatkan hadiah merupakan lecutan. Jika kita member hadiah pizza kepada anak kita karena prestasi atletiknya, maka apa salahnya jika kita berbuat yang sama kepada murid kita karena prestasi belajarnya.

Ada lima tindakan konkrit dalam meningkatkan prestasi belajar, yang ke empatnya sebagai rangkaian yang bersebab akibat, yaitu sebagai berikut:

1. School Revie adalah proses yang di dalamnya seluruh komponen sekolah bekerjasama dengan pihak-pihak yang relevan, khususnya orang tua siswa dan tenaga profesional untuk mengevaluasi dan menilai efeltifitas kebijakan sekolah, program pelaksanannya, serta mutu lulusannya.

2. Quality Assurance dari data tentang school revie itu, kita dapat berusaha untuk melangkah agar rata-rata kondisi guru menjadi lebih baik, langkah tersebut dapat ditempuh dengan quality assurance.

3. Quality Control adalah suatu system untuk mendeteksi terjadinya penyimpangan kualitas out put yang tidak sesuai dengan standar.

4. Standar Kualitas ini bersifat relative dan dapat dibuat oleh masing-masing lembaga atau sekolah.

5. Bench Marking merupakan kegiatan untuk menetapkan suatu standar baik proses maupun hasil yang akan dicapai dalam suatu periode tertentu.

Prestasi belajar harus mengacu dan dikaitkan pada tujuan instruksional. Hal ini sesuai dengan pernyataan Poerwadarminta "Prestasi belajar menghasilkan perubahan individu yang belajar. Perubahan tersebut merupakan kemampuan dalam berbagai bidang, baik kognitif, afektif maupun psikomotorik yang semula tidak dikuasai. Dan kemampuan-kemampuan itu dihasilkan dari proses belajar yang diwujudkan melalui suatu proses".

Sehubungan dengan kegiatan belajar mengajar disekolah menurut Winkel: "Hasil belajar siswa merupakan prestasi belajar yang berdasarkan kemampuan internal yang 
diperoleh sesuai dengan tujuan instruksional”. Definisi lain dikemukakan oleh Amoes Neoleka "Prestasi belajar adalah tingkat penguasaan yang dicapai oleh siswa dalam proses belajar".

\section{Hakikat Pendidikan Agama Islam}

Istilah Pendidikan Agama Islam dalam bahasa Arab menggunakan kata Tarbiyah Islamiyah. Jika kita menanggapi pertanyaan tentang konsep Tarbiyah, yang te rsirat dalam benak kita adalah jawaban yang sederhana. Namun dikalangan para pakar pendidikan masalah Tarbiyah merupakan masalah yang sangat berarti. Karena itu berbagai perangkat tentang Tarbiyah bermunculan. Dalam bahasa Arab, Tarbiyah berasal dari kata Robbayurobbi atau Robbaba yang artinya memperbaiki sesuatu dan meluruskannya. Imam Baidhowi dalam tafsirnya ketika menafsirkan firman Alloh SWT dalam surat AlFatihah Robbul 'Alamin mengatakan Arrobbu merupakan Mashdar (sebutan) yang bermakna Tarbiyah, yaitu menyampaikan sesuatu sampai menuju titik kesempurnaan sedikit demi sedikit.

Pendidikan Agama Islam adalah model pendidikan yang dikehendaki oleh Islam berdasarkan pada Al-Qur'an dan AlHadits yang telah diterapkan oleh Rosululloh SAW dan para sahabatnya. Pendidikan Islam adalah pendidikan yang melatih kepekaan (sensibility) para peserta didik sedemikian rupa sehingga sikap hidup dan perilaku juga keputusan dan pendekatannya kepada semua jenis pengetahuan dikuasai oleh perasaan mendalam nilai-nilai etis dan spiritual Islam.

\section{Deskripsi Data}

Untuk memperoleh data dalam penelitian ini, penulis menggunakan instrumen berupa angket, wawancara, obsevasi dan dokumentasi. Di dalam penulisan jurnal ini penulis menggunakan dua macam penelitian, yaitu penelitian kepustakaan dan penelitian lapangan.

Dalam penelitian kepustakaan penulis meneliti sejumlah referensi yang berhubungan dengan masalah yang dibahas dalam jurnal ini untuk menguatkan pendapat penulis dan sebagai sandaran yang kuat dari para ahli yang berkompeten dibidangnya. Sedangkan dalam pelaksanaan penelitian lapangan penulis menggunakan teknik pengumpulan data atau instrumen penelitian berupa angket.

\section{Teknik Analisis Data}

Data-data yang diperoleh melalui teknik pengumpulan data (angket) kemudian dianalisa dengan teknik analisa sebagai berikut:

1. Angket yang telah diisi oleh siswa ditabulasikan, yaitu dihitung frekuensi jawabannya.

2. Berdasarkan daftar tabulasi (frekuensi jawaban), selanjutnya data dianalisa, dan dipresentasikan.

Teknik analisa yang digunakan ialah prosentase $\begin{array}{llllll}\text { dengan rumus } & \underline{F} & x & 100 & \%\end{array}$ $N$

Sedangkan untuk menafsirkan data dengan jalan menentukan skala perhitungan dari $1 \%$ sampai dengan $100 \%$ sebagai berikut:

\begin{tabular}{|c|c|}
\hline $100 \%$ & Dinyatakan seluruhnya \\
\hline $99 \%-61 \%$ & $\begin{array}{l}\text { Dinyatakan sebagian } \\
\text { besar }\end{array}$ \\
\hline $60 \%-51 \%$ & $\begin{array}{l}\text { Dinyatakan lebih dari } \\
\text { setengahnya }\end{array}$ \\
\hline $50 \%$ & Dinyatakan setengahnya \\
\hline $49 \%-40 \%$ & $\begin{array}{l}\text { Dinyatakan hampir } \\
\text { setengahnya }\end{array}$ \\
\hline $39 \%-1 \%$ & $\begin{array}{l}\text { Dinyatakan sebagian } \\
\text { kecil }\end{array}$ \\
\hline $0 \%$ & $\begin{array}{l}\text { Dinyatakan tidak ada } \\
\text { sama sekali }\end{array}$ \\
\hline
\end{tabular}

Pada tabel-tabel diatas dapat dilihat bagaimana sesungguhnya respon siswa kelas enam terhadap metode ceramah yang diterapkan oleh guru bidang studi PAI di SD ALMuzzammil Bekasi. Diagram Prestasi Belajar siswa kelas 6 SD AL-Muzzammil tahun 2016-2017, Berdasarkan Raport semester 1 pada bidang studi PAI yang meraih nilai: 


\begin{tabular}{|l|l|}
\hline 9.0 & 5 Orang \\
\hline 8.5 & 4 Orang \\
\hline 8.0 & 4 Orang \\
\hline
\end{tabular}

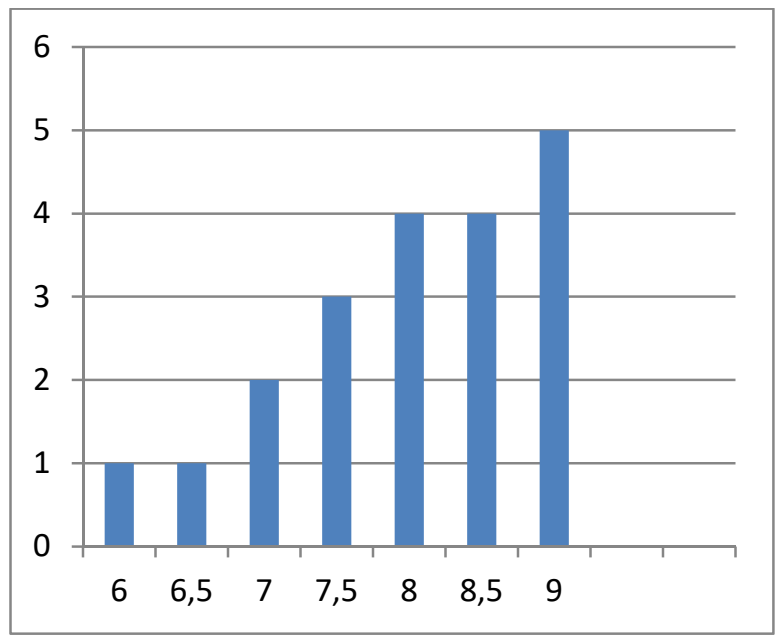

\section{Masalah-masalah yang dihadapi}

a. Guru tidak dapat mengetahui secara pasti sampai dimana para siswa telah mengerti dan memahami penjelasan guru

b. Dalam diri siswa besar kemungkinan akan terbentur konsep-konsep yang lain dari pada kata-kata yang dimaksudkan oleh guru

c. Siswa cenderung bersifat pasif, kurang dapat mengemukakan pendapatnya sehingga inisiatif dan daya kreasinya tertekan.

d. Para siswa agak sulit mengkonsentrasikan perhatian mereka terhadap keterangan guru, terutama pada siang hari.

\section{Usaha-usaha Pemecahan (solusi-solusi)}

a. Susunlah materi pelajaran yang benarbenar perlu diceramahkan, disesuaikan dengan situasi kejiwaan, lingkungan sosial dan lingkungan kebudayaan siswa

b. Gunakan alat peraga waktu berceramah, baik alat peraga langsung maupun alat peraga tidak langsung

\begin{tabular}{|l|ll|}
\hline 7.5 & 3 & Orang \\
\hline 7.0 & 2 & Orang \\
\hline 6.5 & 1 & Orang \\
\hline 6.0 & 1 & Orang \\
\hline
\end{tabular}

c. Berceramahlah dengan gaya menarik, gunakan bahasa yang mudah dipahami. Perlu diperhatikan ucapan, tempo, ritme dan dinamikanya.

d. Jelaskanlah istilah-istilah yang baru dan sulit sebelum pelajaran dimulai

e. Buatlah sistematika ceramah dan adakan rencana penilaian. Teknik penilaian yang wajar digunakan untuk mengetahui tercapai atau tidaknya tujuan-tujuan khusus yang telah ditetapkan.

\section{SIMPULAN}

Berdasarkan pembahasan tersebut, maka dapat diambil simpulan sebagai berikut:

a. Metode Pengajaran yang diterapkan guru bidang studi Pendiidkan Agama Islam (PAI) sesuai dengan GBPP (Garis-garis Besar Program Pengajaran).

b. Materi bidang studi PAI yang diajarkan sesuai dengan kurikulum yang telah ditetapkan.

c. Dalam Penyampaian materi pelajaran, guru bidang studi PAI tidak hanya terpaku pada satu metode saja, akan tetapi juga menggunakan beberapa metode yang disesuaikan dengan situasi dan kondisi.

d. Agar minat belajar siswa bertambah, pihak sekolah sebaiknya melengkapi sarana dan prasarana yang belum ada.

e. Dari tabel peranan metode ceramah yang dilaksanakan pada waktu pemberian angket, metode ceramah berperan dalam meningkatkan prestasi belajar siswa.

Dari hasil penelitian diketahui bahwa metode ceramah berperan dalam meningkatkan prestasi belajar sisiwa pada bidang studi PAI. Namun demikian untuk lebih menarik minat siswa dalam meningkatkan prestasi belajarnya 
pada bidang studi PAI, ada beberapa saran kepada guru bidang studi PAI dan umumnya kepada seluruh guru yang mengajar di SD ALMuttaqin Tasikmalaya, diantaranya:

a. Diharapkan para guru (khususnya guru bidang studi PAI) dapat memilih dan mampu menguasai beberapa metode dalam menyampaikan pelajaran bidang studi masing-masing.

b. Guru diharuskan mampu dalam membantu mengembangkan kreatifitas siswa dalam pembelajaran.

c. Selain dapat menguasai metode-metode dalam mengajar, ada beberapa teknik yang dapat digunakan oleh para guru dalam mengajar, seperti teknik ISTIQOMAH. Teknik ISTIQOMAH, yaitu:

1) Imagination; Bangkitkan imajinasi siswa jauh kedepan, baik itu manfaat ilmu, agar mampu menciptakan teknologi dari yang tidak ada menjadi ada untuk kemakmuran manusia.

2) Student Centre; Aktifkan peran sisiwa, biarkan siswa berperan aktif, namun tetap dalam pengawasan guru

3) Technology; Gunakan simulasi yang unik dan menarik, guru sebaiknya dapat mengajar dengan memanfaatkan teknologi belajar multi inderawi, sehingga membuat siswa senang dalam belajar dan informasi dapat diterima dengan mudah.

4) Intervention; aktifkan siswa dengan dinamis. Guru harus mampu mendesain proses belajar, intervensi terstruktur pada peserta didik serta mampu mengkritisi pengalaman siswanya.

5) Question and Answer; Guru sebaiknya mampu mengajar dengan cara mendorong rasa ingin tahu, merumuskan pernyataan rasa ingin tahu yang dimiliki siswa (Hipotesa), merancang cara menjawab rasa ingin tahu, dan menemukan jawaban.
Jawaban terakhir adalah ilmu pembendaharaan dan kosa kata.

6) Organization; ajaran hidup teratur dan dapat mendokumentasikan pengalaman belajarnya dengan baik agar dapat digunakan pada waktu yang lain. Guru sebaiknya turut mengontrol pola pengorganisasian ilmu yang telah diperoleh oleh siswa. Hindari banyak bermain, sikap sekali belajar mampu menerapkan.

7) Motivation; bangkitkan gairah belajarnya dengan melibatkan aspek emosi positif siswa dan dirinya, kemudian bangkitkan semangat belajar dan motivasi belajarnya.

8) Aplication; jangan hanya jadi beo, bicara tanpa makna dan tanpa realita, orang senang belajar yang praktis. Guru dalam mengajar hendaknya mampu memvisualisasikan ilmu pengetahuan pada dunia praktis, atau mampu berpikir lateral untuk mengembangkan aplikasi ilmu tersebut dalam berbagai bidang kehidupan. Ilmu tanpa amal akan siasia dalam belajar.

9) Heart (Spiritual); belajar adalah tanggung jawab dunia akhirat, bangkitkan nilai-nilai spiritualnya dalam belajar, guru harus mampu membangkitkan kekuatan spiritual kepada peserta didik.

d. Guru harus mampu memilih metode pembelajaran yang efektif

e. Guru harus mampu mengembangkan kecerdasan emosi

f. Guru harus mampu mendisiplinkan peserta diidk dengan kasih sayang.

\section{DAFTAR PUSTAKA}

Abu Ridha, (1994). Pentingnya Pendidikan Dalam Islam. Jakarta: Inqilab Press. 
Abdul Aziz Masyhuri, (1982). Mutiara AlQur'an dan Al-Hadits. Surabaya: Ikhlas Press.

Ahmad Syafii Maarif, (1995). Membumikan Islam. Yogyakarta: Pustaka Pelajar.

Alie As'ad, (1978). Terjemah Kitab Ta'limul Mutaallim. Kudus: Menara Kudus.

Abu Zakariya Yahya Anawawiy, (1985). Syarhul Arba'in. Surabaya: Maktabah Ahmad Nabhan.

Departemen Agama RI, (1990). Terjemah AlQur'anul Karim. Jakarta: Depag Press.

Amoes Noeleka, (1986). Pengantar Penelitian. Jakarta: Grafindo Utama.

Bakhtiar Surin, (1978). Tafsir Tematik AlQur'an. Bandung: FA Sumatera.

Dirjen Pembinaan Depag RI, (1986). Proses Belajar Mengajar. Jakarta: Depag Press.

Fadhlan Mudhofar, (2000). Krisis Dalam Pendidikan Islam. Jakarta: ALMawardi Press.

Fakhruddin Nursyam, (1994). Tarbiyyah Rosululloh SAW. Jakarta: Gema Insani Press.

Hilmy Bakar Al-Mascatiy, (1999). Membangun Sistem Pendidikan Islam. Jakarta: UNIA Press.

Hilmy Bakar Al-Mascatiy, (1995). Generasi Penyelamat Umat. Jakarta: UNIA Press.

Team Prima Pena, (1996). Kamus Besar Bahasa Indonesia. Jakarta: Gita Media Press.

Mansyur Syah, (1992). Materi Pokok Strategi Belajar Mengajar. Jakarta: Depag Press.

Hasan Al-Banna, (1998). Majmu'at Arrosaail Al-Imam Hasan Al-Banna. Cairo: Darud Da'wah.

Moh. Nur Abd Hafidz, (1994). Mendidik Anak Bersama Rosululloh. Jakarta: Gema Insani Press.
Moh. Ngalim Purwanto, (1984). Psikologi Pendidikan. Bandung: Rosda Karya.

Moh. Yaqzan, (1993). Penomena Perbudakan Pemikiran. Jakarta: Al-Ghiroh Press.

Omar Muhammad, (1979). Falsafah Pendidikan Islam. Jakarta: Bintang Bulan Press.

Sholih Fauzan, (2002). Indahnya Bertauhid. Jakarta: Assofwa Press.

Ummu Yasmin, (2002). Materi Tarbiyah. Solo: Media Insani Press.

Wahid Abdusalam, (1992). Kiat Mencetak Anak Sholih. Yogyakarta: Titian Ilahi Press.

Willian Stainback, (1999). Membantu Anak Berhasil Di Sekolah. Jakarta: Kanisius Press.

WS. Winkel, (1982). Psikologi Pengajaran. Jakarta: Balai Pustaka. 